\title{
Alcohol Intoxication Impairs Mesopic Rod and Cone Temporal Processing in Social Drinkers
}

\author{
Xiaohua Zhuang, Para Kang, Andrea King, and Dingcai Cao
}

\begin{abstract}
Background: Alcohol-related driving accidents and fatalities occur most frequently at nighttime and at dawn, that is, a mesopic lighting condition in which visual processing depends on both rod and cone photoreceptors. The temporal functions of the rod and cone pathways are critical for driving in this lighting condition. However, how alcohol influences the temporal functions in the rod and cone pathways at mesopic light levels is inconclusive. To address this, this study investigated whether an acute intoxicating dose of alcohol impairs rod- and/or cone-mediated critical fusion frequency (CFF; the lowest frequency of which an intermittent or flickering light stimulus is perceived as steady).

Methods: In Experiment I, we measured the CFFs for 3 types of visual stimuli (rod stimulus alone, cone stimulus alone, and the mixture of both stimuli types), under 3 illuminant light levels (dim illuminance: $2 \mathrm{Td}$; low illuminance: $20 \mathrm{Td}$; and medium illuminance: $80 \mathrm{Td}$ ) in moderate-heavy social drinkers before and after they consumed an intoxicating dose of alcohol $(0.8 \mathrm{~g} / \mathrm{kg})$ compared with a placebo beverage. In Experiment II, we examined whether the illuminance level (dark vs. light) of the visual area surrounding the test stimuli alters alcohol's effect on the temporal processing of rods and cones.

Results: The results showed that compared with placebo, alcohol significantly reduced CFFs of all stimulus types at all illuminance levels. Furthermore, alcohol intoxication produced a larger impairment on rod-pathway-mediated CFFs under light versus dark surround.

Conclusions: These results indicate that alcohol intake slows down rod and cone-pathway-mediated temporal processing. Further research may elucidate whether this effect may play a role in alcohol-related injury and accidents, which often occur under low-light conditions.

Key Words: Visual Temporal Processing, Rod and Cone Photoreceptors, Alcohol, Mesopic Light Level, Critical Fusion Frequency (CFF).
\end{abstract}

$\mathrm{T}$ HE HUMAN VISUAL system can detect light in a large dynamic range between daytime and nighttime. This is accomplished, in part, by switching operations between 2 photoreceptor classes in the retina, that is, rods and cones. Rods become active under nighttime conditions, including dim light, but are insensitive with bright light. On the other hand, cones need more light to function and they operate best at high-light levels. Therefore, rods and cones are responsible for our night vision and day vision, respectively (Cao, 2012). During the transitional period between daytime and nighttime (i.e., dawn or dusk), both rods and cones are functioning simultaneously to ensure smooth transition between night vision and day vision. In both

From the Department of Ophthalmology \& Visual Sciences (XZ, PK, $D C)$, University of Illinois at Chicago, Chicago, Illinois; and Department of Psychiatry \& Behavioral Neuroscience (AK), University of Chicago, Chicago, Illinois.

Received for publication September 25, 2014; accepted June 28, 2015.

Reprint requests: Dingcai Cao, Department of Ophthalmology \& Visual Sciences, University of Illinois at Chicago, 1905 W. Taylor Street, Chicago, Illinois 60612; Tel.: 312-355-3662; Fax: 312-355-3728; E-mail. dcao98@uic.edu

Present address: Xiaohua Zhuang, Institute for Mind and Biology, The University of Chicago, Chicago, Illinois, 60637.

Copyright (C) 2015 by the Research Society on Alcoholism.

DOI: 10.1111/acer.12833 research and applied fields, different light levels are categorized into 3 different ranges: photopic light level (such as a daylight, when rods are saturated and cones alone mediate vision), mesopic light level (such as a dawn/dusk light, moonlight, or nighttime street light, when both rods and cones are active), or scotopic light level (such as a starlight, when cones are below threshold and rods alone mediate vision).

Most alcohol-related driving accidents or fatalities occur within the mesopic range at nighttime and dawn. There are higher rates of automobile accidents under mesopic light levels compared with photopic light levels, and when combined with alcohol intoxication, the accident rates increase dramatically compared to the rates for daytime accidents (NHTSA, 2010). For situations such as driving in a traffic flow, fast visual temporal processing is critical for public safety. Understanding how alcohol affects temporal processing mediated by the rod and cone pathways under mesopic light levels will help to provide essential knowledge to educate and prevent alcohol-related injury/fatalities in those lighting conditions.

Studies have shown that the rod and cone pathways have different temporal processing characteristics (Cao et al., 2007, 2010; Schneeweis and Schnapf, 1995). A fundamental measure of visual temporal resolution is critical fusion frequency (CFF), which indicates the lowest temporal 
frequency of an intermittent light that appears to be completely steady. With the same temporal modulation contrasts, the cone system has a faster temporal response under mesopic light levels with a CFF range from 11 to $30 \mathrm{~Hz}$ compared with the rod system which has a CFF range from 8 to $15 \mathrm{~Hz}$ (Cao and Lu, 2012; Cao et al., 2006). Acute alcohol intake has been shown to impair visual temporal processing (Khan and Timney, 2007; Kunchulia et al., 2012). Specifically, Pearson and Timney (1999) reported that acute alcohol intoxication impaired photopic (cone-pathway-mediated) CFF but not mesopic (rod- and cone-pathway-mediated) CFF. From this result, they concluded that alcohol intoxication selectively impaired cone- but not rod-mediated temporal processing. These results conflict with the anatomical and single-unit electrophysiological findings showing that at mesopic light levels, rod signals merge into the cone pathway via gap junctions in the retina (Cao et al., 2010; Hornstein et al., 2005) instead of via the rod bipolar cells that are functioning at dimmer light levels, that is, below cone activation threshold (reviewed by Daw et al., 1990; Sharpe and Stockman, 1999). In other words, rod and cone signals are transmitted in the same pathways once rod signal passes the gap junctions. Given that rods and cones share the same retinal neural pathways (reviewed by Daw et al., 1990; Sharpe and Stockman, 1999), it is unclear how acute alcohol intoxication could impair cone function only.

In this study, we examined whether acute alcohol intoxication impairs rod and/or cone temporal function under a mesopic condition using a custom-made device that can generate light stimuli targeting rods and cones separately at the same light levels. Moderate and heavy drinkers were examined because they are at risk for alcohol-related harm, but have not incurred significant withdrawal symptomatology or other physiological consequences that may confound participation (Caetano et al., 1998). We first examined the effects of alcohol on rod- and cone-pathwaymediated CFF at mesopic light levels with the surrounding light levels the same as the light levels for the test stimuli (i.e., an equiluminant surround) in Experiment I (Cao et al., 2010). Additionally, as studies have shown that a dark surround can suppress cone-mediated temporal processing due to lateral rod-cone interaction ( $\mathrm{CaO}$ and $\mathrm{Lu}$, 2012; Cao et al., 2006; Goldberg et al., 1983), we conducted a second experiment to examine alcohol's effect on rod- and cone-pathway-mediated CFF with dark versus equiluminant surround.

\section{EXPERIMENT I}

\section{MATERIALS AND METHODS}

\section{Participants}

Participants were recruited via Internet advertisements. Candidates (age: $21-29$ years) completed informed consent, online screening questionnaires and interview, which included demographic information, medical information (eye disease, heart disease, diabetes, high blood pressure, mental health, etc.), and drinking information (the Alcohol Quantity-Frequency Interview; Cahalan et al., 1969) in past 6 months and the Timeline Follow-Back (TLFB; Sobell and Sobell, 1995; Sobell et al., 1979) calendar for daily estimates of alcohol drinking in the past month. Inclusion criteria were as follows: having normal or corrected-to-normal acuity and reported not having any health and psychiatric problems including alcohol dependence that might interfere with the study procedures. The drinking criteria were as follows: consuming at least 6 or more alcoholic drinks weekly (up to 35) and engaging in binge drinking (consuming 5+ drinks/occasion for men and $4+$ for women; SAMHSA, 2005) at least twice monthly up to 4 times weekly. This moderate-to-heavy drinking inclusion criteria is consistent with prior experimental and epidemiological studies (Abel and Kruger, 1995). Therefore, the participants will form a continuum in terms of drinking patterns from habitual moderate-to-heavy social drinking and with a range of binge drinking frequency from several times monthly to weekly.

Twenty-nine young healthy nonalcoholic moderate-heavy social drinkers (15 males and 14 females, age: 24 [mean] \pm 2.2 [SD] years) met inclusion criteria and thus comprised the study sample. They averaged $11.6 \pm 4.7$ drinking days per month, $4.3 \pm 1.8$ drinks per drinking day, and $5.1 \pm 3.0$ heavy drinking days per month ( 5 or more drinks for men, 4 for women). The study was approved by the Institutional Review Board at The University of Illinois at Chicago and was in compliance with the Declaration of Helsinki.

\section{Overall Design and Protocol}

Each subject participated in a within-subject, double-blinded and placebo-controlled alcohol challenge study using experimental methods similar to those used in previous studies by our group (King et al., 2011, 2014; Rueger et al., 2015; Zhuang et al., 2012). Each participant completed 2 experimental sessions, with administration of alcohol $(0.8 \mathrm{~g} / \mathrm{kg})$ or placebo beverage in each session. Rod- and cone-pathway-mediated CFF was measured before and after beverage consumption. The order of the 2 sessions was randomized, with a minimum of 48-hour intervals between the sessions.

The participant was instructed to abstain from alcohol and recreational drugs for 48 hours prior to each session. Upon arrival to each session, recent alcohol abstinence was verified with a zero breath alcohol concentration (BrAC) level from the Alco-Sensor IV (Intoximeter Inc., St. Louis, MO). The participant first darkadapted his/her right eye by wearing an eyepatch for 15 minutes and then underwent the prebeverage baseline CFF measurement for 15 minutes. After this testing, the participant was then instructed to start consuming the allocated beverage for that session with the experimenter present. Both participant and experimenter were blinded to the beverage content. The participant was given $5 \mathrm{~min}$ utes to finish the first half of the beverage and then had a 5-minute break followed by a 5-minute period to complete the second half of the beverage, as per our prior protocols (Epstein et al., 2007; King et al., 2002, 2011). The participant rested for a 30-minute interval after completing beverage ingestion with the right eye covered by an eye patch during the last 15 minutes of this rest period. This was followed by the postbeverage CFF measurement for 15 minutes. Participants' BrAC levels were measured before and after testing.

The alcoholic beverage consisted of $16 \%$ volume ethanol, which contained 190-proof ethanol mixed with water, grape-flavored drink mix, and a sucralose-based sugar substitute. The alcohol dose was $0.8 \mathrm{~g} / \mathrm{kg}$, that is, equivalent to 4-5 standard alcohol drinks (King et al., 2011; Zhuang et al., 2012). The placebo beverage included $1 \%$ volume ethanol as a taste mask to reduce expectancy effects. Women received $85 \%$ of the dose of men as a correction for body water differences (Oakes and Feldman, 2001). 
The total beverage volume was (mean) $435.3 \pm$ (SD) $81.6 \mathrm{ml}$ for the participants.

\section{Apparatus}

A custom-made 4-LED photostimulator was used to generate visual stimuli for rod- and cone-pathway-mediated CFF testing (Pokorny et al., 2004). The photostimulator consisted of 2 light channels, 1 for the central field and the other for the surround. Each channel was created by mixing lights from 4 LEDs with different colors through an optical diffuser and homogenizer. The dominant wavelengths for the 4 LEDs were 460, 516, 558, and $660 \mathrm{~nm}$, respectively, all with half-bandwidths of about $10 \mathrm{~nm}$. Using the silent substitution method based on well-established rod and cone spectral sensitivity functions (Estévez and Spekreijse, 1982), this apparatus could control rod and cone excitations independently. The details of the theoretical aspects for achieving independent control of rod and cone excitations in a 4-color photostimulator can be found elsewhere (Shapiro et al., 1996). The light levels of the stimuli were specified as photopic Troland (Td, a unit that represents the amount of light falling into the retina by considering both luminance, a light intensity measure based on human luminosity function, and human pupil size), based on the Commission Internationale de l'Eclairage (CIE, International Commission on Illumination) $10^{\circ}$ Standard Observer (Shapiro et al., 1996). For all participants, CFF was measured with the right eye viewing the light modulation through a 2$\mathrm{mm}$ artificial pupil to ensure the amount of light reaching the retina did not change with human pupil size, which could vary with light levels and light modulation (e.g., Barrionuevo et al., 2014; Pokorny and Smith, 1997).

\section{Visual Stimuli and Task}

As stated earlier, dark adaptation was accomplished by having the participant rest for 15 minutes in a dark room with their right eye covered by an eye patch before each of the 2 (the pre- and postbeverage consumption) measurement intervals. A typical dark adaptation curve is obtained after exposure to a bleaching light, in which rods recover sensitivity in 30-40 minutes. When no bleaching light is used, our prior study showed 15 minutes is sufficient to recover rod sensitivity (Feigl et al., 2011). Therefore, 15 minutes is a reasonable choice to minimize the time in the dark, while allowing rod sensitivity recovered approximately to their maximal level. During the CFF measurement, the participant fixated his or her gaze at a white dot positioned at an eccentricity of $7.5^{\circ}$ (in visual angle that accounts for both stimulus size and viewing distance) away from the center of the test area. The stimuli consisted of a circular area (diameter $10^{\circ}$, surround) with a small test area at the center (diameter $2^{\circ}$, center). During the experiment, the light in the center was modulated temporally in a sinusoidal waveform, while the light in the surround was steady and had the same light level as the time-averaged light level of the center. The participant adjusted the temporal frequency of the sinusoidally modulated light to find the lowest temporal frequency at which the central light appeared steady. This temporal frequency was used as the CFF for the participant. The contrast of the sinusoidal modulation was $28 \%$ and the sinusoidal modulation was imbedded in a 1-second raised cosine temporal envelope, that is, $E(t)=E_{0}+0.5\left[1-\cos \left(\frac{2 \pi t}{d}\right)\right]\left[E_{0} \mathrm{C} * \sin (2 \pi f t)\right]$, where $E(t)$ represents photoreceptor excitation at time $t, E_{0}$ for time-average excitation, $d$ for the duration of the envelope, $f$ for frequency, and $C$ for contrast. Three types of stimulus conditions were tested at 3 different stimulus background light levels (an illuminance of 2, 20, and 80 photopic $\mathrm{Td}$, time-averaged illuminance of the center and surround): (i) rod modulation stimuli (rod excitation was modulated, while S-, M-, L-cone excitations were kept constant), (ii) cone-modulation stimuli (S-, M-, L-cone excitations were modulated in the same phases and contrast, while rod excitation was kept constant), and (iii) mixed modulation stimuli (rod and S-, M-, L-cone excitations were modulated in phases). The time-averaged chromaticity in the center, which was the same as the chromaticity in the steady surround, was set as $\mathrm{L} /(\mathrm{L}+\mathrm{M})=0.65$ and $\mathrm{S} /(\mathrm{L}+\mathrm{M})=0.45$ in the MacLeod and Boynton (1979) chromaticity space for all the 3 types of stimuli. The time-averaged illuminance of the center and surround for the stimuli were 2, 20 and 80 $\mathrm{Td}$. The light levels were chosen to cover a range of mesopic light levels where rod and cone have various relative contributions. Our previous results showed that at $2 \mathrm{Tds}$, rods dominate for mesopic temporal processing; at $20 \mathrm{Tds}$, rod and cone contributions are about equal; and at $80 \mathrm{Tds}$, cones dominate but rods are still active (Cao and Lu, 2012; Cao et al., 2005, 2006, 2007, 2008, 2010). The participant performed 4 trials for each stimulus type at each illuminance level, a total of 36 trials ( 4 trials $\times 3$ stimulus types $\times 3$ illuminance levels). In order to minimize the light-adaption effect for the rod and cone pathways (i.e., a reduced rod- or cone-mediated sensitivity due to an exposure to a light that is brighter than the test light level), the CFF measurement was obtained in the order of 2 , 20 , and $80 \mathrm{Td}$ to avoid potential rod and cone sensitivity changes following a high test light level. Similar stimuli and testing procedures have been conducted by our group (Cao and Lu, 2012; Cao et al., 2006). While the within-subject, placebo-controlled design was the strength of this study, and given the fixed order of light levels, order effects could not be completely ruled out to influence our findings.

\section{Data Analysis}

We used paired $t$-tests to compare the CFF changes during the alcohol $\left(\triangle \mathrm{CFF}_{\mathrm{A}}=(\text { Post }- \text { Pre })_{\mathrm{A}}\right)$ and placebo $\left(\Delta \mathrm{CFF}_{\mathrm{P}}=(\text { Post }- \text { Pre })_{\mathrm{P}}\right)$ sessions. As cone-pathway-mediated $\mathrm{CFF}$ was higher than rod-pathway-mediated CFF for the same modulation contrast at the same light level, to compare alcohol effect on rod- and cone-pathway-mediated CFF, we conducted additional analyses to consider the baseline CFF difference between the stimulus types. To do this, the prebeverage measures from the 2 sessions at each light level of each stimulus type were then averaged to form overall baseline CFF measures. Next, to account for baseline CFF difference under various stimulus conditions, a net alcohol effect $\frac{(\text { Post-Pre })_{\mathrm{A}}-(\text { Post-Pre })_{\mathrm{P}}}{\left(\operatorname{Pre}_{\mathrm{A}}+\mathrm{Pre}_{\mathrm{P}}\right) / 2}$ was calculated for each stimulus type at each light level. A negative value indicated impairment from alcohol intoxication compared to placebo. A larger value in absolute term indicated larger impairment. We used a nonparametric KruskalWallis rank test to compare the indices across the 3 types of stimuli under each light level due to the skewed distributions of the indices.

\section{RESULTS}

The BrAC levels were all zero at baseline for both sessions, confirming recent alcohol abstinence in all participants. In the alcohol session, BrAC levels were relatively steady through the 15-minute postbeverage CFF testing (before $\mathrm{CFF}$ BrAC $0.070 \% \pm 0.016$, after $\mathrm{CFF}$ BrAC $0.068 \% \pm 0.011, p=0.362$ ).

Prebeverage CFFs did not differ between sessions for each stimulus type at each light level (Table 1), and values were comparable with previous findings ( $\mathrm{Cao}$ and $\mathrm{Lu}, 2012$; $\mathrm{CaO}$ et al., 2006). Alcohol significantly reduced CFFs for all stimulus types and light levels, as the differences in CFFs between the post- and prebeverage measures in the alcohol sessions 
Table 1. Prebeverage Critical Fusion Frequency in the Alcohol and Placebo Sessions

\begin{tabular}{|c|c|c|c|c|c|c|c|c|c|}
\hline \multirow[b]{2}{*}{ Stimulus type } & \multicolumn{3}{|c|}{$2 \mathrm{Td}$} & \multicolumn{3}{|c|}{$20 \mathrm{Td}$} & \multicolumn{3}{|c|}{$80 \mathrm{Td}$} \\
\hline & Placebo & Alcohol & $p$ & Placebo & Alcohol & $p$ & Placebo & Alcohol & $p$ \\
\hline Rod & $11.0(2.7)$ & $10.6(2.7)$ & 0.35 & 14.0 (3.2) & 13.5 (3.2) & 0.11 & $14.9(6.4)$ & $14.6(5.8)$ & 0.13 \\
\hline Cone & $10.6(2.7)$ & $11.2(2.8)$ & 0.24 & $19.9(2.9)$ & $19.7(2.6)$ & 0.25 & 27.5 (3.2) & 26.7 (3.2) & 0.20 \\
\hline Mixed & $11.6(2.4)$ & $11.3(1.7)$ & 0.33 & $19.6(2.9)$ & $19.3(2.2)$ & 0.82 & $27.2(3.3)$ & $27.1(2.9)$ & 0.63 \\
\hline
\end{tabular}

Table 2. Postbeverage Critical Fusion Frequency in the Alcohol and Placebo Sessions

\begin{tabular}{|c|c|c|c|c|c|c|}
\hline \multirow[b]{2}{*}{ Stimulus type } & \multicolumn{2}{|c|}{$2 \mathrm{Td}$} & \multicolumn{2}{|c|}{$20 \mathrm{Td}$} & \multicolumn{2}{|c|}{$80 \mathrm{Td}$} \\
\hline & Placebo & Alcohol & Placebo & Alcohol & Placebo & Alcohol \\
\hline Rod & $11.1(3.2)$ & 10.0 (3.1) & 13.5 (2.9) & $12.0(2.9)$ & 14.5 (3.1) & $12.7(2.9)$ \\
\hline Cone & $10.8(2.4)$ & $9.9(2.8)$ & $20.1(4.2)$ & $18.6(4.3)$ & $27.6(5.0)$ & $25.3(5.3)$ \\
\hline Mixed & $12.0(2.1)$ & $10.8(1.4)$ & $20.0(3.4)$ & $18.1(3.1)$ & 26.9 (3.9) & 25.7 (3.9) \\
\hline
\end{tabular}

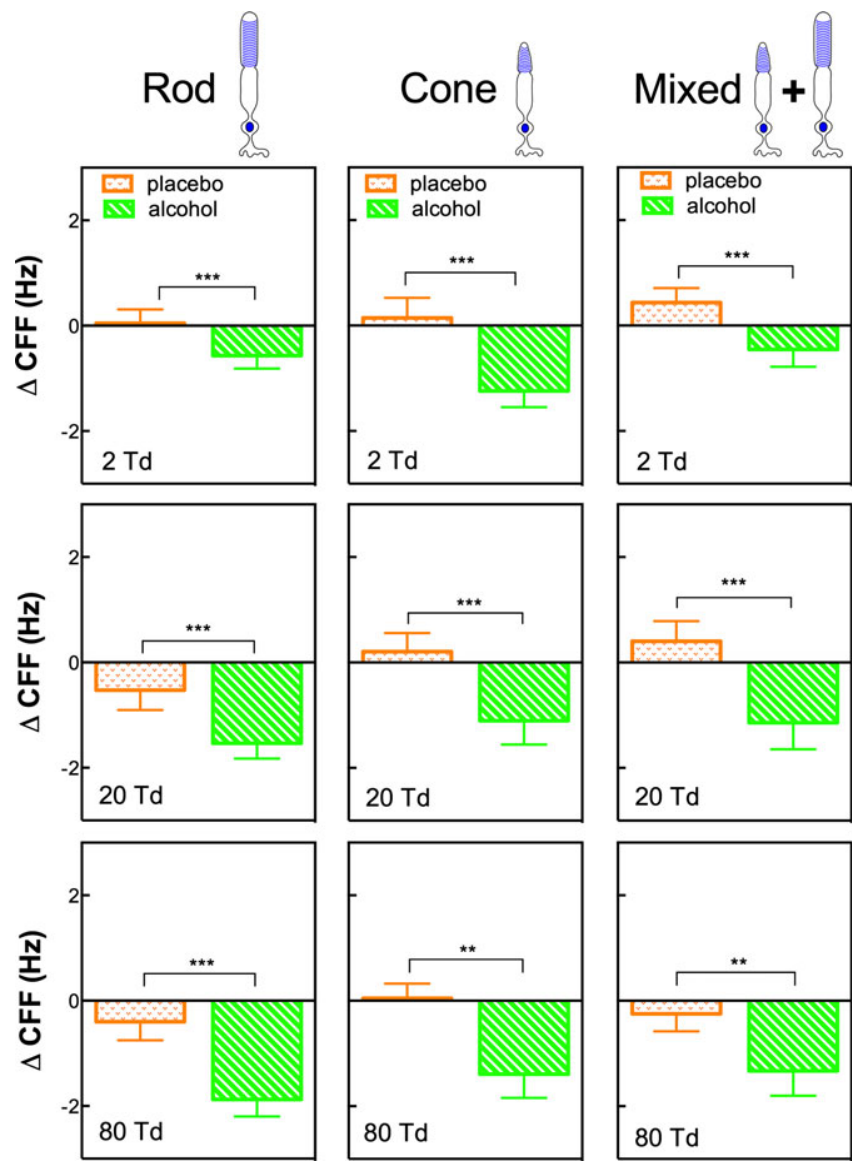

Fig. 1. Differences of critical fusion frequencies (CFFs) between postand prebeverage measures in the placebo and alcohol session for each stimulus type. The left, middle, and right columns are for rod, cone, and mixed stimuli, respectively. The top, middle, and bottom panels are results for 2,20 , and 80 Td illuminance levels, respectively. ${ }^{* \star} p<0.01,{ }^{* * *} p$ $<0.001$.

were significantly greater than those in the placebo session (see Fig. 1 and Table 1-3). Further, the net alcohol effects, quantified as $\frac{(\text { Post-Pre })_{A}-(\text { Post-Pre })_{\mathrm{P}}}{\left(\operatorname{Pre}_{\mathrm{A}}+\mathrm{Pre}_{\mathrm{P}}\right) / 2}$, were significantly different
Table 3. Statistical Test Results Comparing $\Delta \mathrm{CFF}_{\mathrm{A}}$ and $\Delta \mathrm{CFF}_{\mathrm{P}}$ in Experiment 1

\begin{tabular}{lcccccccc}
\hline & \multicolumn{2}{c}{$2 \mathrm{Td}$} & & \multicolumn{2}{c}{$20 \mathrm{Td}$} & & \multicolumn{2}{c}{$80 \mathrm{Td}$} \\
\cline { 2 - 3 } \cline { 8 - 9 } \cline { 8 - 9 } Stimulus type & $t$ & $p$ & & $t$ & $p$ & & $t$ & $p$ \\
\hline Rod & -2.87 & 0.008 & & -4.32 & 0.0002 & & -4.92 & $<0.0005$ \\
Cone & -3.70 & 0.001 & & -3.22 & 0.003 & & -2.75 & 0.010 \\
Mixed & -2.89 & 0.007 & & -4.40 & 0.0001 & & -2.48 & 0.019
\end{tabular}

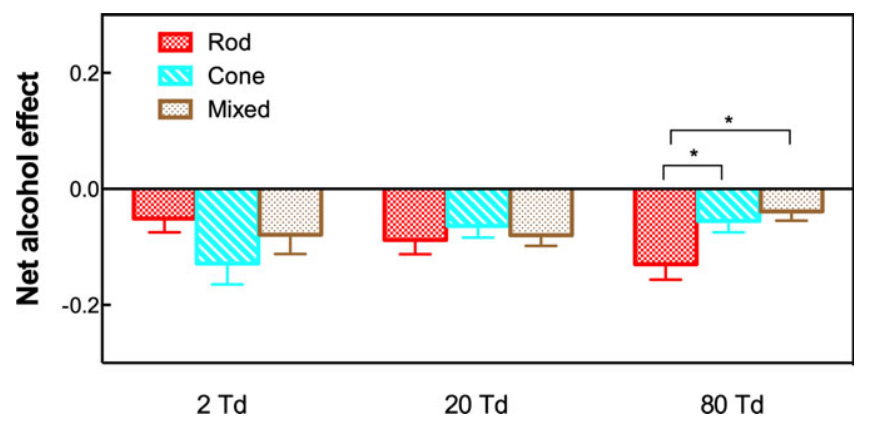

Fig. 2. Net alcohol effect $\frac{\left(\text { Post-Pre }_{A}-(\text { Post-Pre })_{\mathrm{P}}\right.}{\left(\operatorname{Pre}_{A}+\mathrm{Pre}_{\mathrm{P}}\right) / 2}$ or each stimulus type at each illuminance level in Experiment I. ${ }^{*} p<0.05$.

across stimulus types at $80 \mathrm{Td}$ but not at $2 \mathrm{Td}$ and $20 \mathrm{Td}$. At $80 \mathrm{Td}$, alcohol produced a greater impairment in rod modulation stimuli than cone or mixed modulation stimuli $\left(\chi^{2}=7.00, p=0.03\right.$; Fig. 2$)$. These results indicate that alcohol impaired both rod- and conepathway-mediated CFFs at mesopic lighting conditions and there was more impairment for rod than cone function at $80 \mathrm{Td}$.

\section{EXPERIMENT II}

\section{MATERIALS AND METHODS}

To test whether lateral rod-cone interaction in flicker detection (Cao and Lu, 2012; Cao et al., 2006; Goldberg et al., 1983) can 

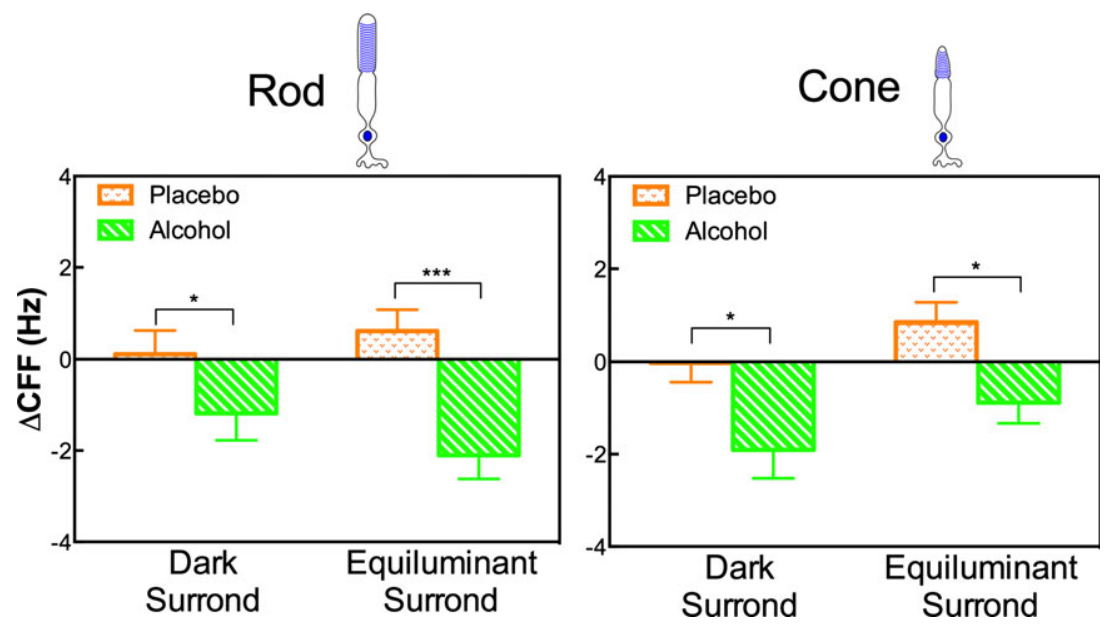

Fig. 3. Differences of critical fusion frequencies (CFFs) between post- and prebeverage measures in the placebo and alcohol session for rod and cone under dark and equiluminant surround illuminance. ${ }^{\star} p<0.05,{ }^{* \star *} p<0.001$.

Table 4. Statistical Test Results Comparing $\Delta \mathrm{CFF}_{\mathrm{A}}$ and $\Delta \mathrm{CFF}_{\mathrm{P}}$ in Experiment 2

\begin{tabular}{lccccc}
\hline & \multicolumn{2}{c}{ Dark surround } & & \multicolumn{2}{c}{ Equiluminant surround } \\
\cline { 2 - 3 } \cline { 6 - 6 } Stimulus type & $t$ & $p$ & & $t$ & $p$ \\
\hline Rod & -2.51 & 0.024 & & -5.31 & $<0.0005$ \\
Cone & -2.57 & 0.021 & & -2.64 & 0.018 \\
\hline
\end{tabular}

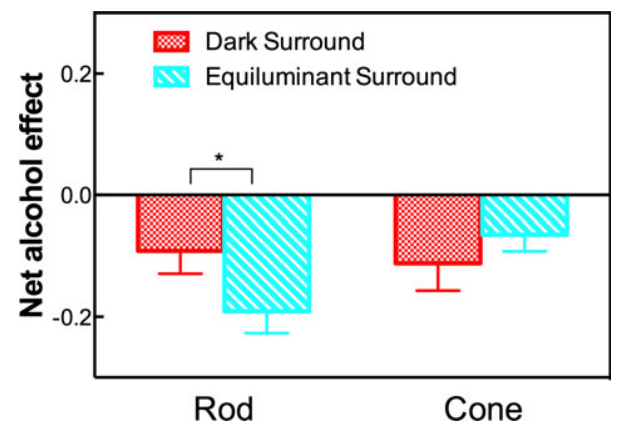

Fig. 4. Net alcohol effect $\frac{(\text { Post-Pre })_{A}-(\text { Post-Pre })_{\mathrm{P}}}{\left.\text { Pre }_{\mathrm{P}}+\text { Prep }\right) / 2}$ or rod and cone under dark and equiluminant surround illuminance in Experiment II. ${ }^{*} p<0.05$.

affect alcohol's effect on CFF, Experiment II measured alcohol's effect on CFF with an equiluminant surround or a dark surround. Procedures for participant screening, alcohol and placebo beverage administration, and visual testing were the same as those in Experiment I. What differed in this second experiment was that the rod and cone stimuli were tested at the illuminance of $80 \mathrm{Td}$, with either an equiluminant or dark surround. We tested the dark surround first then equiluminant surround to minimize the light-adaption effect by bright surrounding light. A Wilcoxon signed-rank test was used to compare the indices between the 2 conditions for each stimulus type. We examined an independent sample of 16 non-alcohol-dependent social drinkers (9 males and 7 females, age: $27.1 \pm 5.56$ years) using similar screening procedures as in Experiment I. Participants were similar to those in the prior experiment in terms of demographic characteristics and alcohol drinking patterns (averages of $8.0 \pm 4.8$ drinking days per month, $3.3 \pm 2.3$ drinks per drinking day, $3.5 \pm 3.7$ heavy drinking days per month).

\section{RESULTS}

Compared with placebo, alcohol significantly impaired both rod- and cone-pathway-mediated CFF in both the dark and equiluminant surround conditions (Fig. 3 and Table 4). Further, alcohol produced more impairment for rod-pathway-mediated CFF under the equiluminant surround condition as compared with the dark surround condition (Fig. 4; $z=2.086, p=0.039$ ). In contrast, alcohol's impairment of cone-pathway-mediated CFF was similar for these surround conditions (Fig. 4; $z=-0.931, p=0.352$ ), suggesting that a dark surround did not alter alcohol's effect on mesopic cone temporal processing.

\section{DISCUSSION}

While alcohol impairment of visual functions under lowlighting conditions (mesopic light levels) has been well-established, alcohol's effects on rod temporal functions have been inconclusive. The present study showed that acute alcohol intoxication impairs both rod and cone temporal functions at mesopic light levels. As CFFs with the rod and cone stimuli are likely mediated by the magnocellular pathway, our results suggest that an intoxicating dose of alcohol significantly impaired temporal processing that is likely mediated by the magnocellular pathway, which is consistent with our prior study demonstrating alcohol impaired contrast sensitivity in the magnocellular pathway, but not the parvocellular pathway (Zhuang et al., 2012).

Interestingly, our results also indicate that under equiluminant surrounds, acute alcohol intoxication impaired the rod-pathway-mediated temporal processing more than the cone-pathway-mediated temporal processing at $80 \mathrm{Td}$ (Experiment I; Fig. 2), or more severe impairment for 
rod-pathway-mediated temporal processing at equiluminant than dark surround lighting conditions at $80 \mathrm{Td}$ (Experiment II; Fig. 4). It is known that with increasing light levels at mesopic range rod contribution relative to cone contribution to temporal processing decreases (Cao et al., 2010). At 80 $\mathrm{Td}$, cone contribution dominates mesopic temporal processing, as evidenced by 2 results from the CFF measurement at the placebo session (Tables 1 and 2; $80 \mathrm{Td}$ ). First, the conepathway-mediated CFF $(\sim 27.5 \mathrm{~Hz})$ was $12.6 \mathrm{~Hz}$ higher than the rod-pathway-mediated CFF $(\sim 14.9 \mathrm{~Hz})$. Second, the cone-pathway-mediated $\mathrm{CFF}(\sim 27.5 \mathrm{~Hz})$ was close to the CFF mediated by mixed rod and cone pathways $(\sim 27.2 \mathrm{~Hz})$. These results implied that at a given mesopic light level, the impairment of alcohol intoxication on the rod-pathway-mediated temporal processing likely depends on the strength of rod input relative to cone input in mesopic vision. On the other hand, a dark surround can suppress rod- or cone-pathway-mediated CFF, potentially via distal interaction in the retina (Cao and Lu, 2012; Cao et al., 2006). Assuming rod signals are transmitted through rod-cone gap junctions at mesopic light levels and rod-cone coupling strength is modulated by local or distal light adaptation (Frumkes and Eysteinsson, 1987, 1988; Ribelayga et al., 2008; Yang and $\mathrm{Wu}, 1989 \mathrm{a}, \mathrm{b})$, we speculated that alcohol may impact lightadaptation-dependent rod-cone coupling strength. More research is needed to assess the mechanisms how alcohol affects rod and cone functions under different stimulation conditions.

In general, our results support previous studies of alcohol's slowing of visual processing (Edden et al., 2009; Khan and Timney, 2007; Kunchulia et al., 2012; Moskowitz and Murray, 1976; Pearson and Timney, 1998). Further, our results showed that alcohol-induced impairments did not differ across the 2 stimulus types (rod, cone, and rod-cone mixed) at 2 and $20 \mathrm{Tds}$, consistent with the hypothesis that rod signals are transmitted through the rod-cone gap junction pathways at these mesopic light levels (Daw et al., 1990; Sharpe and Stockman, 1999).

Although studies have reported that alcohol reduced electroretinogram amplitudes under dark adaptation, suggesting alcohol impairment of rod functions (Ikeda, 1963), our results are the first reporting a deficit from alcohol on rod temporal processing using a psychophysical approach. The current study used an instrument that could independently stimulate rods and cones. This approach has been used in other basic science studies and has been shown to be an effective way to investigate rod and cone temporal functions under various mesopic light levels (Cao and $\mathrm{Lu}$, 2012; Cao et al., 2006, 2007; Feigl et al., 2011; Zele and Cao, 2015). The current study was the first to use this instrument to study alcohol effects on rod- and cone-pathway functions.

Our main finding of alcohol impairment of both cone- and rod-pathway CFFs at mesopic light levels is inconsistent with the results of Pearson and Timney (1999) study. In their study, they reported alcohol impairment on cone-pathway-mediated CFFs, but they did not find an alcohol effect on rod-pathway-mediated CFFs under mesopic light levels. Further, our second experiment showed that alcohol significantly impaired rod-pathway-mediated CFFs under both surrounding illuminant conditions, suggesting that difference in surrounding illuminance cannot completely explain the discrepancy between the current results and those of Pearson and Timney (1999) regarding alcohol impairment on rod-pathway-mediated CFF. The discrepancy is possibly due to the differences in the testing conditions and the methodologies used in the 2 studies, such as sinusoidal waveforms in our study versus square-wave waveforms in their studies, and a silent substitution method used in our study but not in their study. Furthermore, 1 unexpected finding in their study was that the CFFs under photopic light level of $22 \mathrm{~cd} / \mathrm{m}^{2}(\sim 220 \mathrm{Td}$; Le Grand, 1957) decreased with increasing retinal eccentricity, but other literature indicated that CFFs increased with increasing eccentricity (Rovamo and Raninen, 1988).

Previous studies show that alcohol affects the function of several neurotransmitters found in both the central nervous system and retina (Boileau et al., 2003; Eckardt et al., 1998; Van Breukelen, 2006; Wang et al., 2000; Weiner and Valenzuela, 2006). For example, glutamate-related transmitters are critical for excitatory visual processing (Liang and Zeger, 2000; Van Breukelen, 2006), and dopamine- and GABA-related inhibitory transmitters play an important role in inhibitory processes of visual processing (Chavez et al., 2010; Daw et al., 1990; Herrmann et al., 2011; Vigh et al., 2011; Witkovsky, 2004; Yang et al., 2013). Furthermore, based on results from animal studies, acute alcohol administration is known to increase GABA concentration levels in the brain (Grobin et al., 1998) and potentially in the retina. Therefore, the reduction in rodand cone-pathway-mediated CFFs under the influence of alcohol might be attributed to relative changes in the balance of excitatory and inhibitory neural processing in the retina as well as in the cortex. Another possibility is that alcohol intake increases phototransduction noise in photoreceptors or neuronal processing noise in the cortex, reducing sensory information processing efficiency at these sites (Pokorny, 2011). A recent functional magnetic resonance imaging study (Esposito et al., 2010) reported that alcohol selectively enhanced the spontaneous restingstate blood oxygenation level-dependent fluctuations in the primary visual cortex, which might cause impairment on activation responses to visual stimuli, therefore impairing visual functions.

In conclusion, the current study demonstrated that acute alcohol drinking slowed down temporal processing in the rod and cone pathways at mesopic (low) light levels. Further research is needed to elucidate whether this impairment, independently or in combination with alcohol's effects on other systems, such as psychomotor and cognitive systems, may contribute to the high rates of alcohol-related accidents and injury under low-lighting conditions. 


\section{ACKNOWLEDGMENTS}

This study was supported by ABMRF/Foundation for Alcohol Research (DC), National Institute on Alcohol Abuse and Alcoholism R01-AA013746 (AK), Cless Family Foundation, P30-EY01792 (UIC core grant for vision research), and Unrestricted Departmental Grant from the Research to Prevent Blindness.

\section{REFERENCES}

Abel EL, Kruger ML (1995) Hon v. Stroh Brewery Company: what do we mean by "moderate" and "heavy" drinking? Alcohol Clin Exp Res 19:1024-1031.

Barrionuevo P, Nicandro N, McAnany JJ, Zele AJ, Gamlin PD, Cao D (2014) Assessing relative rod, cone and melanopsin contributions to pupil flicker responses. Invest Ophthalmol Vis Sci 55:719-727.

Boileau I, Assaad JM, Pihl RO, Benkelfat C, Leyton M, Diksic M, Dagher A (2003) Alcohol promotes dopamine release in the human nucleus accumbens. Synapse 49:226-231.

Caetano R, Clark CL, Greenfield TK (1998) Prevalence, trends, and incidence of alcohol withdrawal symptoms: analysis of general population and clinical samples. Alcohol Health Res World 22:73-80.

Cahalan D, Cisin IH, Crossley HM (1969) American drinking practices: a national study of drinking behavior and attitudes, in Monograph, Vol. 6 (Rutgers Center of Alcohol Studies ed), pp. 1-260. Publication Division of Rutgers Center of Alcohol Studies, New Brunswick, NJ.

Cao D (2012) Color vision and night vision, in Retina, 5th ed., Vol. 1 (Ryan SJ ed), pp 285-299. Elsevier Saunders, New York.

Cao D, Lee BB, Sun H (2010) Combination of rod and cone inputs to in the parasol ganglion cells of the magnocellular pathway. J Vis $10: 4,1-15$.

Cao D, Lu Y (2012) Lateral suppression of mesopic rod and cone flicker detection. J Opt Soc Am 29:A188-A193.

Cao D, Pokorny J, Smith VC (2005) Matching rod percepts with cone stimuli. Vision Res 45:2119-2128.

Cao D, Pokorny J, Smith VC, Zele AJ (2008) Rod contributions to color perception: linear with rod contrast. Vision Res 48:25862592.

Cao D, Zele AJ, Pokorny J (2006) Dark-adapted rod suppression of cone flicker detection: evaluation of receptoral and postreceptoral interactions. Vis Neurosci 23:531-537.

Cao D, Zele AJ, Pokorny J (2007) Linking impulse response functions to reaction time: rod and cone reaction time data and a computational model. Vision Res 47:1060-1074.

Chavez AE, Grimes WN, Diamond JS (2010) Mechanisms underlying lateral GABAergic feedback onto rod bipolar cells in rat retina. $\mathbf{J}$ Neurosci 30:2330-2339.

Daw NW, Jensen EJ, Brunken WJ (1990) Rod pathways in the mammalian retinae. Trends Neurosci 13:110-115.

Eckardt MJ, File SE, Gessa GL, Grant KA, Guerri C, Hoffman PL, Tabakoff B (1998) Effects of moderate alcohol consumption on the central nervous system. Alcohol Clin Exp Res 22:998-1040.

Edden RA, Muthukumaraswamy SD, Freeman TC, Singh KD (2009) Orientation discrimination performance is predicted by GABA concentration and gamma oscillation frequency in human primary visual cortex. $\mathrm{J}$ Neurosci 29:15721-15726.

Epstein AM, Sher TG, Young MA, King AC (2007) Tobacco chippers show robust increases in smoking urge after alcohol consumption. Psychopharmacology 190:321-329.

Esposito F, Pignataro G, Di Renzo G, Spinali A, Paccone A, Tedeschi G, Annunziato L (2010) Alcohol increases spontaneous BOLD signal fluctuations in the visual network. NeuroImage 53:534-543.

Estévez O, Spekreijse H (1982) The "silent substitution" method in visual research. Vision Res 22:681-691.
Feigl B, Cao D, Morris CP, Zele AJ (2011) Persons with age-related maculopathy risk genotypes and clinically normal eyes have reduced mesopic vision. Invest Ophthalmol Vis Sci 52:1145-1150.

Frumkes TE, Eysteinsson T (1987) Suppressive rod-cone interaction in distal vertebrate retina: intracellular records from Xenopus and Necturus. J Neurophysiol 57:1361-1382.

Frumkes TE, Eysteinsson T (1988) The cellular basis for suppressive rod cone interaction. Vis Neurosci 1:263-273.

Goldberg SH, Frumkes TE, Nygaard RW (1983) Inhibitory influence of unstimulated rods in the human retina: evidence provided by examining cone flicker. Science 221:180-182.

Grobin AC, Matthews DB, Devaud LL, Morrow AL (1998) The role of GABAA receptors in the acute and chronic effects of ethanol. Psychopharmacology 139:2-19.

Herrmann R, Heflin SJ, Hammond T, Lee B, Wang J, Gainetdinov RR, Arshavsky VY (2011) Rod vision is controlled by dopamine-dependent sensitization of rod bipolar cells by GABA. Neuron 72:101-110.

Hornstein EP, Verweij J, Li PH, Schnapf JL (2005) Gap-junctional coupling and absolute sensitivity of photoreceptors in Macaque retina. J Neurosci 25:11201-11209.

Ikeda H (1963) Effects of ethyl alcohol on the evoked potential of the human eye. Vision Res 3:155-169.

Khan SA, Timney B (2007) Alcohol slows interhemispheric transmission, increases the flash-lag effect, and prolongs masking: evidence for a slowing of neural processing and transmission. Vision Res 47:1821-1832.

King AC, Houle T, de Wit H, Holdstock L, Schuster A (2002) Biphasic alcohol response differs in heavy versus light drinkers. Alcohol Clin Exp Res 26:827-835.

King AC, McNamara PJ, Hasin DS, Cao D (2014) Alcohol challenge responses predict future alcohol use disorder symptoms: a 6-year prospective study. Biol Psychiatry 75:798-806.

King AC, de Wit H, McNamara PJ, Cao D (2011) Rewarding, stimulant, and sedative alcohol responses and relationship to future binge drinking. Arch Gen Psychiatry 68:389-399.

Kunchulia M, Pilz KS, Herzog MH (2012) How alcohol intake affects visual temporal processing. Vision Res 66:11-16.

Le Grand Y (1957) Light, Colour and Vision. Chapman and Hall, London.

Liang K-Y, Zeger SL (2000) Longitudinal data analysis of continuous and discrete responses for pre-post designs. Sankhyā: The Indian Journal of Statistics Series B 62:134-148.

MacLeod DIA, Boynton RM (1979) Chromaticity diagram showing cone excitation by stimuli of equal luminance. J Opt Soc Am 69:1183-1185.

Moskowitz H, Murray JT (1976) Alcohol and backward masking of visual information. J Stud Alcohol 37:40-45.

NHTSA (2010) Highlights of 2009 motor vehicle crashes. Traffic Saftey Facts Research Note, KOT HS 811 363:1-4.

Oakes JM, Feldman HA (2001) Statistical power for nonequivalent pretestposttest designs. The impact of change-score versus ANCOVA models. Eval Rev 25:3-28.

Pearson P, Timney B (1998) Effects of moderate blood alcohol concentrations on spatial and temporal contrast sensitivity. J Stud Alcohol 59:163173.

Pearson P, Timney B (1999) Differential effects of alcohol on rod and cone temporal processing. J Stud Alcohol 60:879-883.

Pokorny J (2011) Review: steady and pulsed pedestals, the how and why of postreceptoral pathway separation. J Vis 11:7, 1-23.

Pokorny J, Smith VC (1997) How much light reaches the retina? in Colour Vision Deficiencies XIII. Documenta Ophthalmologica Proceedings Series, Vol. 59 (Cavonius CR ed), pp 491-511. Springer, the Netherlands.

Pokorny J, Smithson H, Quinlan J (2004) Photostimulator allowing independent control of rods and the three cone types. Vis Neurosci 21:263-267.

Ribelayga C, Cao Y, Mangel SC (2008) The circadian clock in the retina controls rod-cone coupling. Neuron 59:790-801.

Rovamo J, Raninen A (1988) Critical flicker frequency as a function of stimulus area and luminance at various eccentricities in human cone vision: a revision of Granit-Harper and Perry-Porter laws. Vision Res 28:785-790. 
Rueger SY, Hu H, McNamara P, Cao D, Hao W, King AC (2015) Differences in subjective response to alcohol in heavy-and light-drinking Chinese men versus Caucasian American men. Addiction 110:9199.

SAMHSA (2005) National Survey on Drug Use and Health. Office of Applied Studies, Bethesda, MD.

Schneeweis DM, Schnapf JL (1995) Photovoltage of rods and cones in the macaque retina. Science 268:1053-1056.

Shapiro AG, Pokorny J, Smith VC (1996) Cone-rod receptor spaces, with illustrations that use CRT phosphor and light-emitting-diode spectra. J Opt Soc Am 13:2319-2328.

Sharpe LT, Stockman A (1999) Rod pathways: the importance of seeing nothing. Trends Neurosci 22:497-504.

Sobell LC, Maisto SA, Sobell MB, Cooper AM (1979) Reliability of alcohol abusers' self-reports of drinking behavior. Behav Res Ther 17:157-160.

Sobell LC, Sobell MB (1995) Alcohol Timeline Follow-Back Users' Manual. Addiction Research Foundation, Toronto, Canada.

Van Breukelen GJ (2006) ANCOVA versus change from baseline had more power in randomized studies and more bias in nonrandomized studies. $\mathbf{J}$ Clin Epidemiol 59:920-925.
Vigh J, Vickers E, von Gersdorff H (2011) Light-evoked lateral GABAergic inhibition at single bipolar cell synaptic terminals is driven by distinct retinal microcircuits. J Neurosci 31:15884-15893.

Wang GJ, Volkow ND, Franceschi D, Fowler JS, Thanos PK, Scherbaum N, Felder CA (2000) Regional brain metabolism during alcohol intoxication. Alcohol Clin Exp Res 24:822-829.

Weiner JL, Valenzuela CF (2006) Ethanol modulation of GABAergic transmission: the view from the slice. Pharmacol Ther 111:533-554.

Witkovsky P (2004) Dopamine and retinal function. Doc Ophthalmol 108:17-39.

Yang J, Pahng J, Wang GY (2013) Dopamine modulates the off pathway in light-adapted mouse retina. J Neurosci Res 91:138-150.

Yang XL, Wu SM (1989a) Effects of background illumination on the horizontal cell responses in the tiger salamander retina. J Neurosci 9:815-827.

Yang XL, Wu SM (1989b) Modulation of rod-cone coupling by light. Science 244:352-354.

Zele AJ, Cao D (2015) Vision under mesopic and scotopic illumination. Front Psychol 5(1594):1-15.

Zhuang X, King AC, McNamara PJ, Pokorny J, Cao D (2012) Differential effects of alcohol on contrast processing mediated by the Magnocellular and Parvocellular pathways. J Vis 12(11):16, 1-13. 